\title{
Panorama da transparência passiva e da regulamentação da Lei de Acesso à Informação a partir da Escala Brasil Transparente (EBT) nos municípios do COREDE Missões
}

\author{
Monize Sâmara Visentini \\ Universidade Federal da Fronteira Sul - Cerro Largo - Rio Grande do Sul - Brasil \\ ORCID: https://orcid.org/0000-0001-6233-6106 \\ Micheli dos Santos \\ Universidade Federal da Fronteira Sul - Cerro Largo - Rio Grande do Sul - Brasil \\ ORCID: https://orcid.org/0000-0002-3975-2539
}

\section{Resumo}

O presente artigo objetiva investigar a regulamentação da Lei de Acesso à Informação (Lei 12.527/2011) e a realidade da transparência passiva nos 25 municípios integrantes do COREDE Missões, em seus portais eletrônicos, por meio da aplicação da Escala Brasil Transparente (EBT). A pesquisa classifica-se como descritiva, de abordagem quantitativa. A partir dos dados coletados foi comprovado que apenas $28 \%$ do total dos municípios investigados (Caibaté, Cerro Largo, Giruá, Porto Xavier, São Paulo das Missões, São Luiz Gonzaga e São Nicolau) regulamentaram a LAI por instrumento legal (Lei ou Decreto) e que $36 \%$ foram considerados pouco transparentes na forma passiva. A partir desses e outros achados, apresenta-se um diagnóstico da atual situação da transparência na gestão pública municipal no âmbito do COREDE Missões, permitindo aos cidadãos conhecer melhor o ambiente onde vivem e investem, a fim de que consigam refletir sobre a eficiência na gestão pública e a suficiência ou não das informações disponibilizadas, para assim poder intervir no processo de formulação de políticas públicas que possam auxiliar no desenvolvimento regional.

Palavras-chave: Transparência. Lei de Acesso à Informação. Municípios. Portais Eletrônicos. Accountability.

Overview of passive transparency and regulation of the Law on Access to Information from the Brazilian Transparency Scale (EBT) in the municipalities of COREDE Missões

Abstract

The present article aims to investigate the regulation of the Law on Access to Information LAI (Law 12,527 / 2011) and the reality of passive transparency in the 25 municipalities that are members of COREDE Missões, in its website, through the application of the Brazilian Transparency Scale (EBT). The research is classified as descriptive, with a quantitative 
approach. From the data collected, it was verified that only $28 \%$ of the total of the municipalities investigated (Caibaté, Cerro Largo, Giruá, Porto Xavier, São Paulo das Missões, São Luiz Gonzaga e São Nicolau) regulated LAI, by legal instrument (Law or Decree) and that $36 \%$ were considered as non-transparent in the passive form. From these and other findings, we present a diagnosis of the current situation of transparency in municipality public management within the framework of COREDE Missões, allowing citizens to better understand the place in which they live and invest, so that they can reflect on efficiency in public management and the sufficiency or not of the information available, so as to be able to intervene in the process of formulating public policies that may aid in regional development.

Keywords: Transparency. Law of Access to Information. Municipalities. Website. Accountability.

\section{Panorama de la transparencia pasiva y de la reglamentación de la Ley de Acceso a la Información a partir de la Escala Brasil Transparente (EBT) en los municipios del COREDE misiones}

\section{Resumen}

El presente artículo tiene como objetivo investigar la reglamentación de la Ley de Acceso a la Información (Ley 12.527/2011) y la realidad de la transparencia pasiva en los 25 municipios integrantes del COREDE Misiones, en sus portales electrónicos, por medio de la aplicación de la Escala Brasil Transparente (EBT). La investigación se clasifica como descriptiva, de abordaje cuantitativo. A partir de los datos recolectados se comprobó que sólo el $28 \%$ del total de los municipios investigados (Caibaté, Cerro Largo, Giruá, Porto Xavier, São Paulo das Missões, São Luiz Gonzaga y São Nicolau) reglamentaron la LAl por instrumento legal (Ley o Decreto) y que el $36 \%$ se consideró poco transparente en la forma pasiva. A partir de estos y otros hallazgos, se presenta un diagnóstico de la actual situación de la transparencia en la gestión pública municipal en el marco del COREDE Misiones, permitiendo a los ciudadanos conocer mejor el ambiente donde viven y invierten, a fin de que puedan reflexionar sobre la eficiencia en la gestión pública y la suficiencia, o no, de las informaciones disponibles, para así poder intervenir en el proceso de formulación de políticas públicas que puedan auxiliar en el desarrollo regional.

Palabras-clave: Transparencia. Ley de acceso a la información. Municipios. Portales Electrónicos. Accountability.

\section{Introdução}

A temática transparência na gestão pública vem ganhando destaque nos últimos anos, sendo o acesso à informação reconhecido por importantes organismos da comunidade internacional como direito humano fundamental (CGU, 2013). Prova disso, foi à realização, no ano de 2003 , da Convenção das Nações Unidas contra a corrupção (CNUCC), cujo texto foi aprovado pelo Congresso Nacional por meio do Decreto Legislativo $\mathrm{n}^{\circ} 348$, de 18 de maio de 2005 e posteriormente promulgado pelo Decreto 5687, de 31 de janeiro de 2006, passando a vigorar no Brasil, com força de lei.

Para além do destaque internacional do direito de acesso à informação, outro fator que contribuiu para aceitação dessa prerrogativa foi à democratização de vários países a partir dos anos 90, aliada ao desenvolvimento das tecnologias de informação e comunicação (TICS) que mudaram a relação da sociedade com a informação e o uso que fazem dela. Em 1990 apenas treze países haviam adotado esse tipo de lei, 
enquanto que atualmente cerca de noventa países de todas as regiões do mundo já possuem leis nacionais de acesso à informação (CGU, 2013).

De acordo com Angélico (2012), a implantação de uma lei de acesso à informação pode ser realizada em um processo "de cima para baixo" ou de "baixo para cima" e no Brasil esta implantação ocorreu em um processo "de cima para baixo", separando as figuras formuladoras das políticas das figuras que executam estas políticas. Neste cenário, o que motiva a realização deste trabalho é a ideia de que mais do que atender as prerrogativas legais impostas pela legislação vigente, deve-se permitir que a transparência na gestão pública, através da disponibilização do acesso à informação, se constitua em uma política de gestão que garanta o exercício da cidadania e o consequente controle social. Com foco no nível municipal, foi abordada a questão da regulamentação da Lei de Acesso à Informação e a transparência passiva, considerando que a implantação da lei não se encerra no processo de criação de Portais ou Sistemas de Informação ao Cidadão - SIC's, pelo contrário, a implementação da Lei é o início de um diálogo contínuo entre a Administração Pública e a sociedade, na busca por melhores caminhos para a gestão pública (CGU, 2013).

Ao analisar a gestão pública em nível municipal, prioriza-se o espaço local; mesmo sabendo da importância das políticas macro é em âmbito local que a vida flui, que as pessoas interagem e preocupam-se com os problemas que querem ver resolvidos, sendo fundamental valorizar este espaço para viabilizar a prática da cidadania, facilitar a vida social e, o desenvolvimento local (ABREU; LEOPOLDINO; MELO, 2008).

É o contexto apresentado acima que ancora o estudo aqui empreendido, direcionado a partir da formulação da seguinte problemática: Qual a realidade da transparência passiva e da regulamentação da LAI nos municípios do COREDE Missões? Buscando respostas à problemática, o objetivo principal consistiu em avaliar nos portais eletrônicos dos municípios do COREDE Missões, o grau de cumprimento às normas da Lei de Acesso à Informação (Lei 12.527/2011), por meio da aplicação da EBT (Escala Brasil Transparente).

O artigo está organizado em cinco seções, iniciando por esta introdução. A próxima seção discorre sobre os aspectos teóricos que sustentam o objeto de investigação: transparência na gestão pública. A terceira seção contempla o percurso metodológico adotado. Os resultados são apresentados na quarta seção, trazendo um panorama da situação da transparência passiva e da regulamentação da LAI nos municípios do COREDE Missões, e a quinta e última seção aborda as considerações finais sobre a pesquisa.

\section{Transparência na gestão pública}

O foco da transparência está em reduzir as divergências informacionais entre os cidadãos e os gestores públicos, através de ações que exponham as atividades destes gestores. Filgueiras (2011) traduz o conceito de transparência como um valor indispensável à gestão pública contemporânea. Aduz o autor que ao promover a transparência o ente público permite ao cidadão o acesso a informações acerca das ações realizadas pelos agentes públicos e, deste modo, incentiva a accountability. 
O objetivo da transparência deve ser garantir ao cidadão, de forma individual, o acesso às informações que transmitam o desempenho dos governantes, explicitando as ações que estão em andamento, às executadas em períodos anteriores e as que estão em fase de planejamento, através de ampla divulgação por meio eletrônico e realização de audiências públicas, nas quais devem ser disponibilizados os planos, diretrizes orçamentárias, orçamentos, relatórios periódicos da execução orçamentária e da gestão fiscal, bem como das prestações de contas e pareceres prévios emitidos pelos tribunais de contas (SILVA, 2009). A informação deve estar disponível a qualquer tempo, sendo que um governo transparente não se limita apenas em disponibilizar informações relacionadas à sua gestão, mas também a deixar disponíveis informações de gestões anteriores a sua, para que os cidadãos tenham a possibilidade de traçar um paralelo que lhes permita acompanhar a evolução da máquina pública (SILVA, 2009).

Desta forma, a transparência torna-se um dos fragmentos da publicidade, garantida pela Lei Complementar 131/2009 - Lei da Transparência, porém, engloba mais que o princípio da publicidade, previsto na Constituição Federal de 1988, pois traz a possibilidade da participação do cidadão na gestão pública, permitindo ao mesmo conhecer e intervir nos projetos, planos e ações públicas. Seu propósito é vedar ações imprevistas e impróprias como, por exemplo, o uso indevido do patrimônio público, por parte dos gestores, ampliando o acesso dos cidadãos as informações públicas, em todas as esferas, com a finalidade de construir um país mais democrático, propiciando à sociedade desempenhar o controle social, colaborando na efetivação de uma gestão mais eficaz e eficiente (SOUZA et al., 2009).

Em geral, a legislação brasileira tem normatizado elementos mínimos que devem ser considerados no exercício da transparência pelos gestores públicos, priorizando a chamada transparência fiscal. A Lei 12.527/2011 (conhecida como Lei de Acesso à Informação - LAI) foi implantada a nível nacional, como uma política pública de transparência e accountability, cuja aplicabilidade se dá a todas as unidades federativas. Tal dispositivo garante ao cidadão um direito constitucional, ao mesmo tempo em que impõe à União, seus entes, Estados e Municípios a responsabilidade pelo seu atendimento. A legislação obriga além do cumprimento da transparência ativa ${ }^{1}$, já exigida pela Lei de Responsabilidade Fiscal, o cumprimento da transparência passiva².

Segundo Gomes Filho (2005), ao implementar qualquer política de transparência na gestão pública deve-se considerar duas perspectivas, sendo a primeira relacionada a disposição de abertura por parte de quem é detentor do poder, no sentido de retirar obstáculos ao acesso à informação por parte daqueles sobre quem o poder é exercido; e a segunda referente a disposição de informar,

1 De acordo com o Art. $7^{\circ}$ do Decreto №7.724/2012, "é dever dos órgãos e entidades promover, independente de requerimento, a divulgação em seus sítios na Internet de informações de interesse coletivo ou geral por eles produzidas ou custodiadas, observado o disposto nos arts. $7^{\circ}$ e $8^{\circ}$ da Lei $\mathrm{N}^{\circ} 12.527 / 2011 "$.

$2 \mathrm{O}$ Art. $9^{\circ}$ do Decreto $\mathrm{N}^{\circ}$ 7.724/2012, prevê que, "os órgãos e entidades deverão criar Serviço de Informações ao Cidadão - SIC, com o objetivo de: atender e orientar o público quanto ao acesso à informação; informar sobre a tramitação de documentos nas unidades; e receber e registrar pedidos de acesso à informação".

Segundo Hoch, Rigui e Silva (2012), a transparência passiva refere-se ao meio pelo qual o poder público é provocado mediante requerimento do cidadão, a fornecer informações detalhadas de seu interesse. 
disponibilizando informações suficientes a visibilidade do poder diante daqueles sobre quem ele se exerce.

Diante do exposto, conceitua-se a expressão "acesso à informação pública" como à materialização do conceito de transparência pública (ANGÉLICO, 212), podendo-se dizer que somente existe transparência na gestão pública se houver a possibilidade de participação do cidadão (CASALI, 2014). Nesta perspectiva, transparência tem como função deixar-se visível, indo muito além da simples disponibilização de informações, sendo necessária a possibilidade de interação entre o ente que divulga estas informações e o sujeito social que se interessa por tal informação (CASALI, 2014).

Nesse sentido, criada pela Controladoria Geral da União (CGU) em 2015, a Escala Brasil Transparente (EBT) é uma metodologia para mensurar a transparência pública em estados e municípios brasileiros, com o propósito de investigar o grau de cumprimento de dispositivos da Lei de Acesso à Informação (LAl). A aplicação desta metodologia oferece a divulgação de uma métrica, que atribui uma nota de 0 a 10 pontos, sendo $25 \%$ da nota atribuída para a regulamentação da LAI e $75 \%$ para a efetiva existência e atuação dos Serviços de Informação ao Cidadão (SIC).

Mesmo a EBT sendo uma metodologia recentemente criada, pesquisadores a tem utilizado para investigar como os municípios do Brasil vêm atendendo suas obrigações frente à LAl, citando-se Dantas (2015) que realizou um estudo de caso sobre transparência e controle social na gestão pública brasileira, com base na legislação, ferramentas e avanços recentes e Arruda (2016), que investigou a transparência subnacional, através das variáveis determinantes para o atendimento da LAI nos municípios brasileiros. Esta escala também será o foco desta investigação, sendo utilizada para verificar nos municípios de abrangência do COREDE Missões, o grau de cumprimento às normas da LAl e a transparência passiva.

\section{Metodologia}

A pesquisa caracteriza-se como descritiva, a qual busca descrever as características de determinada população ou fenômeno ou o estabelecimento de relações entre variáveis, a partir da utilização de técnicas padronizadas de coleta de dados como questionários, entrevistas e a observação (GIL, 2008). Neste caso, a coleta de dados foi realizada por meio de observação estruturada, nos portais eletrônicos das 25 prefeituras municipais que pertencem ao COREDE Missões, para verificação do grau de cumprimento às normas da Lei de Acesso à Informação (Lei 12.527/2011), por meio da aplicação da EBT (Escala Brasil Transparente) e a realidade da transparência passiva. Desta forma, trata-se de uma pesquisa quantitativa, que segundo Malhotra (2001, p. 155) "procura quantificar os dados e aplica alguma forma de análise estatística". Considerando o tamanho da amostra, optou-se por realizar um estudo censitário. A Figura 1 indica a localização dos municípios que compõem a região. 
Figura 1. Localização dos Municípios no COREDE Missões

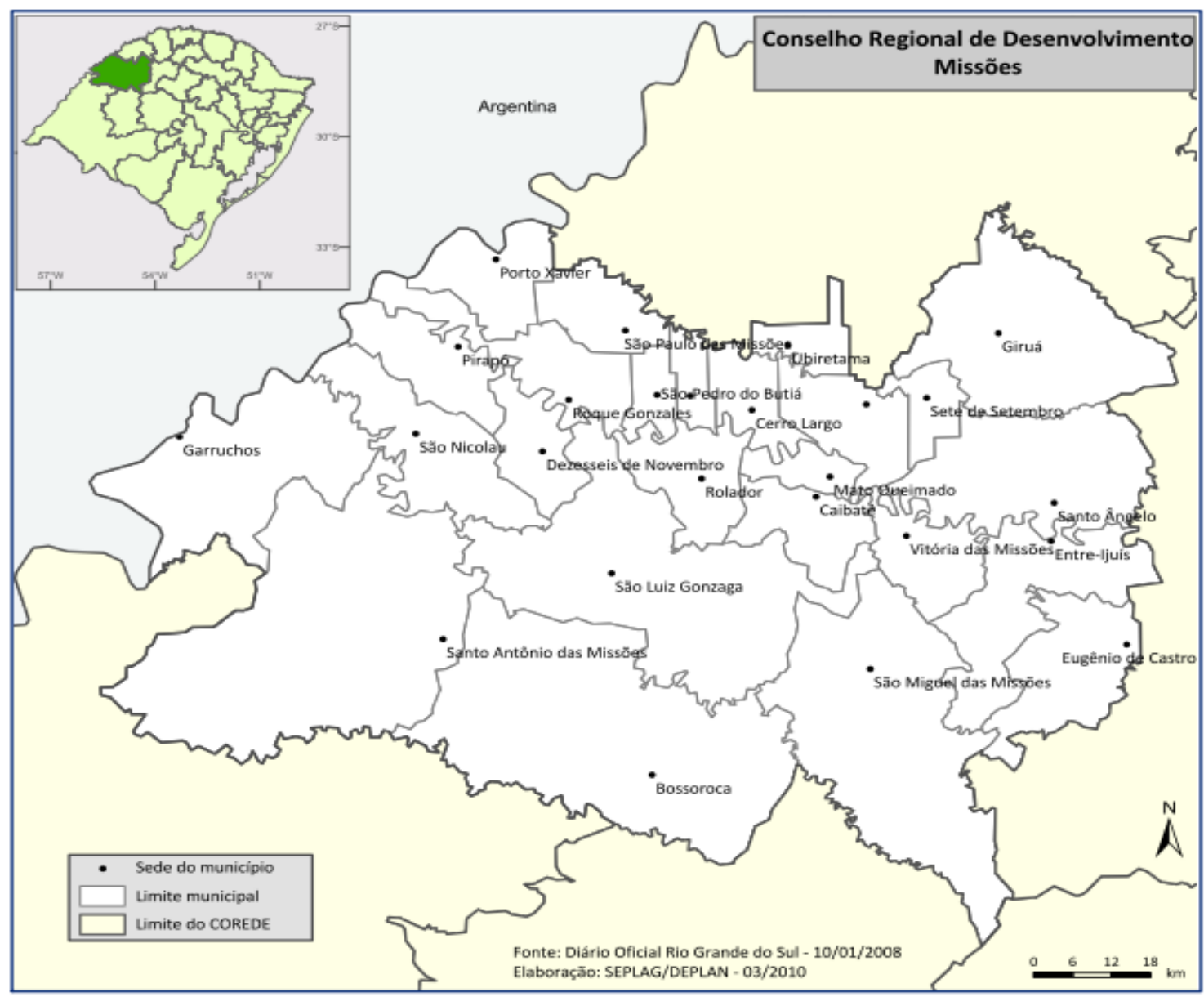

A investigação dos municípios compreendeu a aplicação do checklist da EBT nos portais eletrônicos institucionais.

\subsection{A EBT}

Criada pela Controladoria Geral da União (CGU) em 2015, a Escala Brasil Transparente (EBT) é uma metodologia para mensurar a transparência pública em estados e municípios brasileiros, com o propósito de investigar o grau de cumprimento de dispositivos da Lei de Acesso à Informação (LAI). Pela recente criação, a CGU realizou duas rodadas (EBT 1.0 e EBT 2.0), divulgadas em maio e novembro de 2015, sendo que na primeira rodada foram avaliados $\mathbf{5 1 9}$ entes federativos, sendo 465 municípios com até 50 mil habitantes, todas as 27 capitais, além dos 26 estados e o Distrito Federal; na segunda rodada foram investigados $\mathbf{1 . 6 1 3}$ entes federativos, sendo $\mathbf{1 . 5 5 9}$ municípios, todas as $\mathbf{2 7}$ capitais, além dos $\mathbf{2 6}$ estados e o Distrito Federal. Na amostra dos municípios foram incluídos todos os 492 municípios avaliados na EBT 1.0, além dos que solicitaram a sua avaliação (105 municípios).

Dos 25 municípios investigados nesta pesquisa, apenas 5 haviam recebido avaliação da CGU, sendo eles Guarani das Missões, Pirapó, Roque Gonzales, São Paulo das Missões e Vitória das Missões. Neste estudo, reavaliamos estes municípios, juntamente com os demais, a fim de verificar como estes vêm implementando suas 
obrigações frente à LAI, priorizando de acordo com a EBT, a análise do cumprimento das exigências de transparência passiva e de classificação de informações.

A aplicação desta metodologia oferece a divulgação de uma métrica, que atribui uma nota de 0 a 10 pontos, sendo $25 \%$ da nota atribuída para a regulamentação da LAI e 75\% para a efetiva existência e atuação dos Serviços de Informação ao Cidadão (SIC). O preenchimento do checklist é binário, permitindo as respostas "SIM" ou "NÃO", com a exceção de inexistência de portal eletrônico ou, se este estiver fora do ar, podendo nessa situação utilizar os termos "Não Localizado" ou "Site Fora do AR".

Os portais eletrônicos foram observados e avaliados no período de outubro de 2016 a março de 2017, primeiro na coleta de dados e depois na revisão da coleta, utilizando como parâmetro para o recolhimento dos dados a avaliação da regulamentação da LAI e a transparência passiva, por meio da existência e funcionamento do Sistema de Informação ao Cidadão (SIC), através da resposta do questionamento constante no Quadro 1.

\begin{tabular}{|c|c|c|}
\hline $\mathbf{N}^{\circ}$ & Fato & Capitulação Legal \\
\hline 1 & Foi localizada a regulamentação da LAI pelo Poder Executivo? & $\begin{array}{l}\text { Art. } 42 \\
\text { Lei }{ }^{\circ} 12.527 / 11\end{array}$ \\
\hline 2 & $\begin{array}{l}\text { Na regulamentação, existe a previsão para autoridades } \\
\text { classificarem informações quanto ao grau de sigilo? }\end{array}$ & $\begin{array}{l}\text { Art. } 27 \\
\text { Lei } n^{\circ} 12.527 / 11 \\
\end{array}$ \\
\hline 3 & $\begin{array}{l}\text { Na regulamentação existe a previsão de responsabilização do } \\
\text { servidor em caso de negativa de informação? }\end{array}$ & $\begin{array}{l}\text { Art.32 } \\
\text { Lei } \mathrm{n}^{\circ} 12.527 / 11 \\
\end{array}$ \\
\hline 4 & $\begin{array}{l}\text { Na regulamentação existe a previsão de pelo menos uma instância } \\
\text { recursal? }\end{array}$ & $\begin{array}{l}\text { Art. } 15 \\
\text { Lei } n^{\circ} 12.527 / 11\end{array}$ \\
\hline 5 & $\begin{array}{l}\text { Foi localizada no site a indicação quanto à existência de um SIC } \\
\text { Físico (atendimento presencial)? }\end{array}$ & $\begin{array}{l}\text { Inciso I, Art. } 9^{\circ} \\
\text { Lei }^{\circ} 12.527 / 11\end{array}$ \\
\hline 6 & $\begin{array}{l}\text { Foi localizada alternativa de enviar pedidos de forma eletrônica ao } \\
\text { SIC? }\end{array}$ & $\begin{array}{l}\S 2^{\circ}, \text { Art. } 10^{\circ} \\
\text { Lei } n^{\circ} 12.527 / 11\end{array}$ \\
\hline 7 & $\begin{array}{l}\text { Para a realização dos pedidos de informação, são exigidos apenas } \\
\text { dados que não impossibilitem ou dificultem o acesso? }\end{array}$ & $\begin{array}{l}\S 1^{\circ},{\text { Art. } 10^{\circ}}^{\circ} \\
\text { Lei }^{\circ} 12.527 / 11\end{array}$ \\
\hline 8 & $\begin{array}{l}\text { Foi localizado no site a possibilidade de acompanhamento dos } \\
\text { pedidos realizados? }\end{array}$ & $\begin{array}{l}\text { Inciso I, alíneas "b" e "c" } \\
\text { Art.9 }{ }^{\circ} \text {, Lei n } 12.527 / 11\end{array}$ \\
\hline 9 & Os pedidos enviados foram respondidos no prazo? & $\begin{array}{l}\oint \oint 1^{\circ} \text { e } 2^{\circ}, \text { Art. }^{\circ} 1^{\circ} \\
\text { Lei n }^{\circ} 12.527 / 11\end{array}$ \\
\hline 10 & $\begin{array}{l}\text { Os pedidos de acesso à informação foram respondidos em } \\
\text { conformidade com o que se foi solicitado? }\end{array}$ & $\begin{array}{l}\text { Art.5 } \\
\text { Lei n }^{\circ} 12.527 / 11\end{array}$ \\
\hline
\end{tabular}

Fonte: CGU (2015).

Municípios com população inferior a 10.000 (dez mil) habitantes não têm obrigatoriedade de criar portais eletrônicos, devendo disponibilizar as informações relacionadas à gestão pública de todos os outros modos possíveis, como por exemplo, nos murais internos da Prefeitura Municipal, programas de rádio, jornais de circulação regional, audiências públicas, etc, não sendo, entretanto, dispensados de cumprir com a Lei da Transparência (Lei Complementar n 131/2009). A população da pesquisa constitui-se em sua maioria de municípios de pequeno porte, sendo que apenas $24 \%$ dos municípios possuem população superior a 10.000 habitantes. Entretanto, todos os municípios da região em análise disponibilizam portais eletrônicos institucionais, viabilizando a aplicação e análise da EBT. 
Para tratamento dos dados, foi utilizada a estatística descritiva, constituída de um conjunto de métodos destinados à organização e descrição dos dados através de indicadores sintéticos ou sumários (SILVESTRE, 2007). Os dados foram tabulados, filtrados e analisados em planilha do Microsoft Excel.

\section{Resultados}

Em vigor desde o ano de 2012, a LAl vem sendo implementada pelos municípios brasileiros, existindo ainda prefeituras cujos portais não estão devidamente estruturados para receber solicitações do cidadão (RAUPP, 2016). Para acompanhar este processo, a CGU criou, no ano de 2015, a EBT, aplicada nesta pesquisa nos vinte e cinco municípios que compõem o COREDE Missões, a fim de apresentar um diagnóstico da situação da transparência nesta região.

Com base nos critérios de avaliação e na análise documental realizada nos ambientes web, atendendo ao questionamento 1 (Quadro 1), foi comprovado que apenas sete do total dos municípios investigados (Caibaté, Cerro Largo, Giruá, Porto Xavier, São Paulo das Missões, São Luiz Gonzaga e São Nicolau), correspondendo a $28 \%$, regulamentaram a LAI por instrumento legal (Lei ou Decreto).

O simples fato de regulamentar através de dispositivo legal o acesso à informação não garante que o mesmo esteja ocorrendo na prática. Daí a importância da transparência passiva, entendida como a obrigação do Estado em disponibilizar a todo o cidadão que solicite o acesso a documentos oficiais, exceto aqueles protegidos em razão de segurança nacional, direitos de terceiros ou segurança pública (ZUCCOLOTTO; TEIXEIRA; RICCIO; 2015). A Figura 2 apresenta a regulamentação da LAl em âmbito municipal no COREDE Missões.

Figura 2. Regulamentação da LAl em âmbito municipal no COREDE Missões

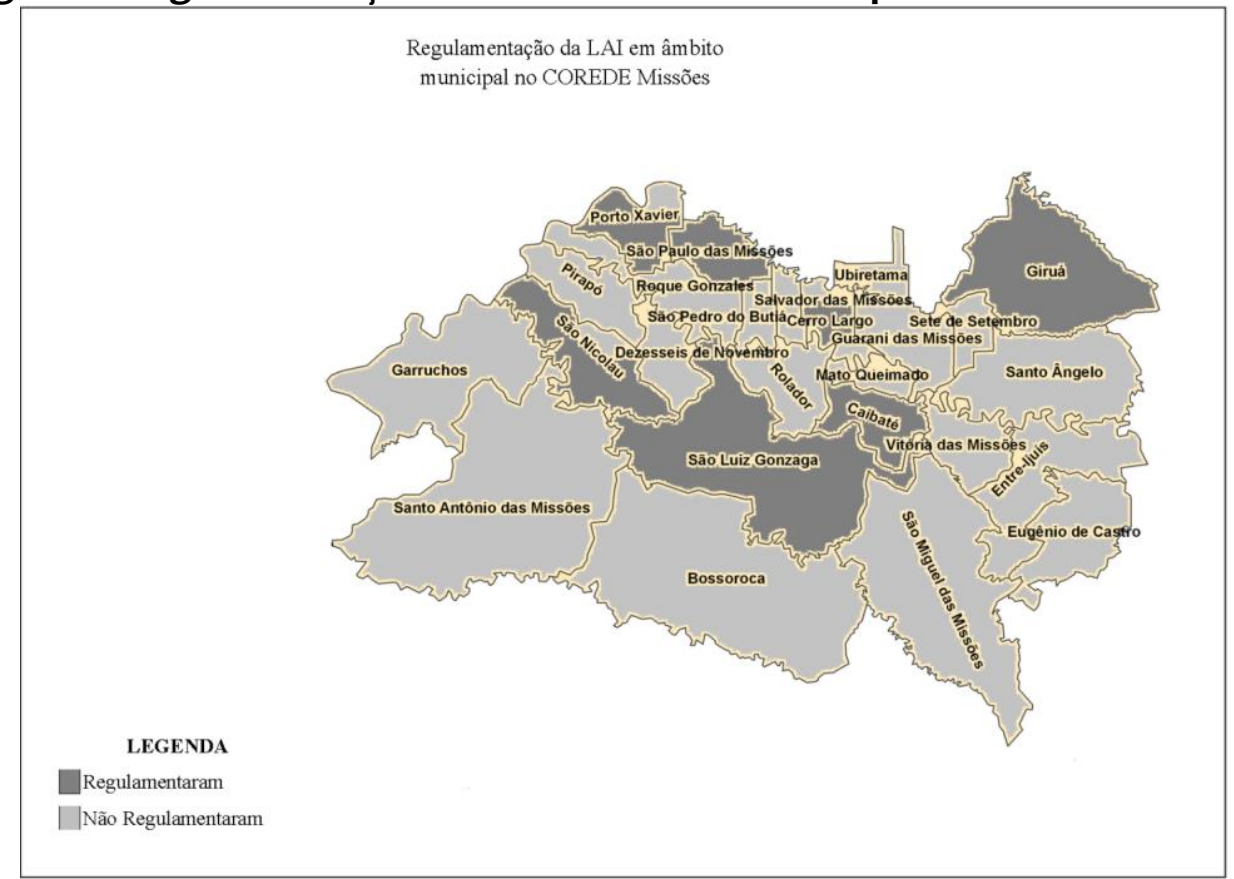

Fonte: Dados da pesquisa (2017).

Atendendo as questões 2, 3 e 4 (Quadro 1), nota-se que a Legislação que regulamenta o acesso à informação nos municípios que se adequaram à LAI, em geral 
tem atendido ao que ela preconiza. Quanto à localização no portal, da indicação quanto à existência de um SIC Físico para atendimento presencial ao cidadão, apenas dois municípios não cumprem com este quesito, Bossoroca e Salvador das Missões.

Quanto a questão 5 , os requisitos necessários para que o cidadão possa efetuar um pedido de acesso à informação de forma presencial é o nome do órgão para a entrega do pedido, endereço, telefone, horários de funcionamento e o agente público responsável pelo portal de acesso à informação. A Figura 3 apresenta a visão da homepage do portal eletrônico do município de Porto Xavier e serve como exemplo do que deve conter na indicação da existência do SIC presencial no portal eletrônico.

Figura 3. Exemplo de indicação de SIC Presencial no Portal Eletrônico

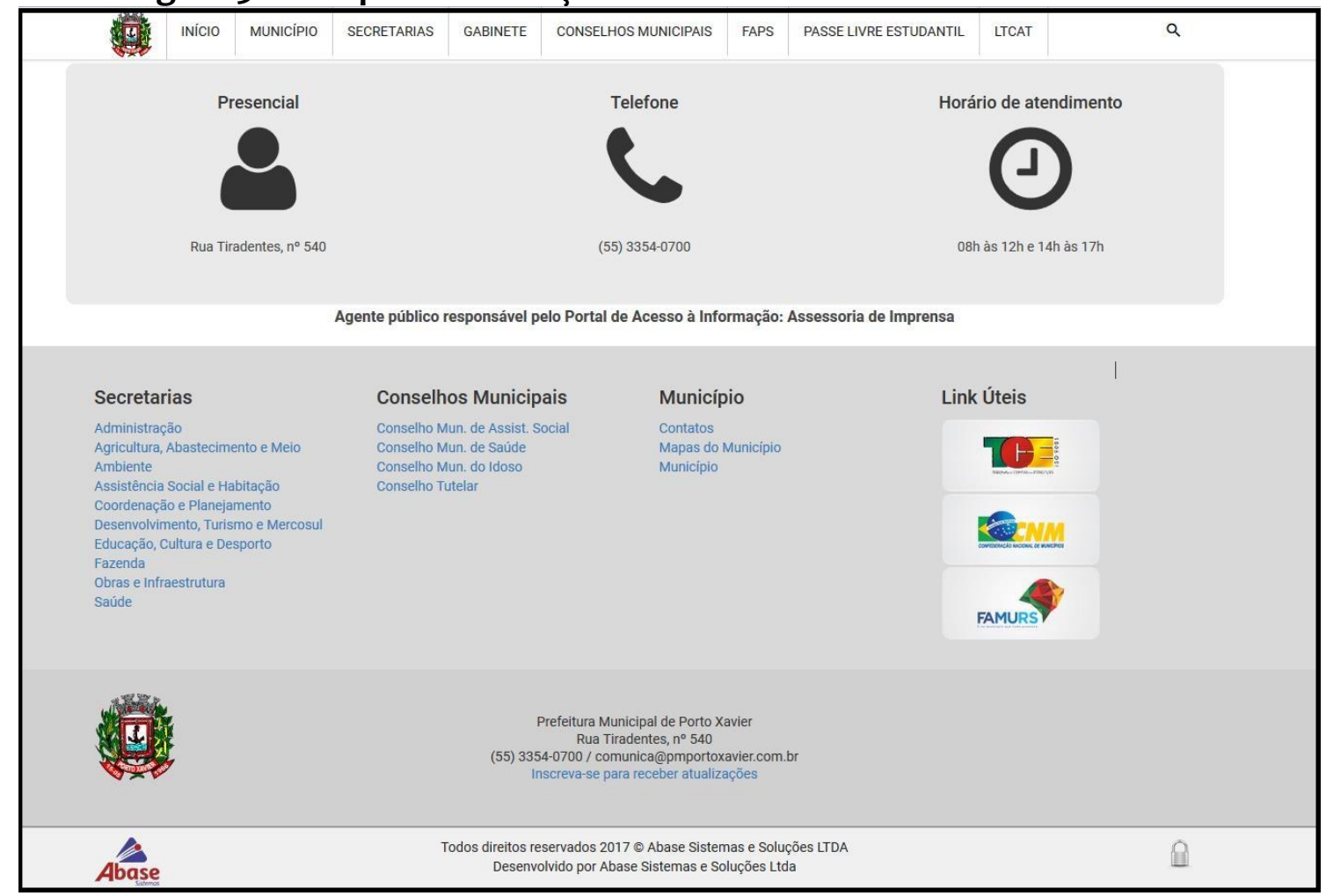

Fonte: Portal eletrônico município de Porto Xavier (2017).

Observa-se que a Figura 3 apresenta os requisitos necessários para que o cidadão possa efetuar um pedido de acesso à informação de forma presencial, disponibilizando o nome do órgão para a entrega do pedido, endereço, telefone, horários de funcionamento e o agente público responsável pelo portal de acesso à informação, no caso, o ocupante do cargo de Assessor de Imprensa, conforme determina a legislação. Destaca-se que $72 \%$ dos municípios não regulamentaram a LAI por meio de dispositivo legal e não formalizaram o SIC, mas mesmo assim criaram em seus portais eletrônicos ou o sistema de Ouvidoria ou o Fale Conosco, possibilitando a comunicação do cidadão com a gestão pública. Este resultado foi obtido a partir do acompanhamento dos portais eletrônicos dos municípios que compõem a população deste estudo, no período de outubro de 2016 a março de 2017, primeiro na coleta de dados e depois na revisão dos dados coletados. 
Respondendo do questionamento 6 ao 10, do Quadro 1, foram enviados aos 25 municípios, via SIC eletrônico, quatro pedidos reais de acesso à informação, em quatro áreas distintas, conforme orientação metodológica do guia de aplicação da EBT (CGU, 2015), conforme detalhado no Quadro 2.

\section{Quadro 2. Pedidos reais de acesso à informação, encaminhados aos municípios do} COREDE Missões

\begin{tabular}{|l|l|}
\hline \multicolumn{1}{|c|}{ Área } & \multicolumn{1}{c|}{ Pedido de Acesso } \\
\hline Saúde & $\begin{array}{l}\text { Solicito, com base na Lei de Acesso à Informação, que me seja enviada uma } \\
\text { relação com os hospitais mantidos pelo governo do estado que disponibilizam } \\
\text { atualmente o tratamento de quimioterapia. }\end{array}$ \\
\hline Educação & $\begin{array}{l}\text { Solicito, com base na Lei de Acesso à Informação, que me seja enviada uma } \\
\text { relação contendo as escolas da rede estadual de ensino, que possuem Educação } \\
\text { para Jovens e Adultos (EJA), atualmente em funcionamento. }\end{array}$ \\
\hline $\begin{array}{l}\text { Assistência } \\
\text { Social }\end{array}$ & $\begin{array}{l}\text { Solicito, com base na Lei de Acesso à Informação, que me seja enviada uma } \\
\text { relação com os programas de governo na área da assistência social que deverão } \\
\text { ser executados no exercício de 2016. }\end{array}$ \\
\hline $\begin{array}{l}\text { Regulamentação } \\
\text { da Lei de Acesso } \\
\text { à Informação }\end{array}$ & $\begin{array}{l}\text { Venho, por meio desta solicitação, pedir que me seja enviado o normativo } \\
\text { (Decreto e/ou Lei Municipal) que regulamentou a Lei de Acesso à Informação no } \\
\text { município. Caso não exista, solicito que seja informado também. }\end{array}$ \\
\hline
\end{tabular}

Fonte: Adaptado de CGU (2015).

Por meio do encaminhamento destes pedidos de acesso, foi possível observar a realidade do cumprimento da transparência passiva pelas prefeituras municipais, e considerando o tempo disponibilizado para as respostas ao pedido que é de 20 (vinte) dias, prorrogáveis por mais 10 (dez) dias, de acordo com a própria Lei 12.527/2011, os mesmos foram encaminhados por via eletrônica, recebendo avaliação no período de 06/10/2016 a 21/11/2016 e posteriormente revisados no período de janeiro a março de 2017. Para este acompanhamento, foi elaborado o Quadro 3.

\section{Quadro 3. Quantitativo dos pedidos de acesso não respondidos por município}

\begin{tabular}{|l|l|}
\hline \multicolumn{1}{|c|}{ Município } & \multicolumn{1}{c|}{ Pedidos não atendidos } \\
\hline Bossoroca & 2 - (Assistência Social e Regulamentação da LAl) \\
\hline Caibaté & 1 - (Assistência Social) \\
\hline Cerro Largo & 1 - (Assistência Social) \\
\hline $\begin{array}{l}\text { Dezesseis } \\
\text { Novembro }\end{array}$ & 4 - (Saúde, Educação, Assistência Social e Regulamentação da LAl) \\
\hline Entre ljuís & 4 - (Saúde, Educação, Assistência Social e Regulamentação da LAl) \\
\hline Garruchos & 4 - (Saúde, Educação, Assistência Social e Regulamentação da LAl) \\
\hline Guarani das Missões & 4 - (Saúde, Educação, Assistência Social e Regulamentação da LAl) \\
\hline Pirapó & 4 - (Saúde, Educação, Assistência Social e Regulamentação da LAl) \\
\hline Rolador & 3 - (Educação, Assistência Social e Regulamentação da LAl) \\
\hline Roque Gonzales & 4 - (Saúde, Educação, Assistência Social e Regulamentação da LAl) \\
\hline
\end{tabular}


(conclusão)

\begin{tabular}{|l|l|}
\hline \multicolumn{1}{|c|}{ Município } & \multicolumn{1}{c|}{ Pedidos não atendidos } \\
\hline Salvador das Missões & 4 - (Saúde, Educação, Assistência Social e Regulamentação da LAI) \\
\hline São Luiz Gonzaga & 1 - (Assistência Social) \\
\hline $\begin{array}{l}\text { São Miguel das } \\
\text { Missões }\end{array}$ & 4 - (Saúde, Educação, Assistência Social e Regulamentação da LAI) \\
\hline São Pedro do Butiá & 2 - (Educação e Regulamentação da LAI) \\
\hline Sete de Setembro & 4 - (Saúde, Educação, Assistência Social e Regulamentação da LAI) \\
\hline Vitória das Missões & 1 - (Assistência Social) \\
\hline
\end{tabular}

Fonte: Dados da pesquisa (2017).

No período de revisão dos dados coletados, voltou-se aos portais eletrônicos destes municípios, para verificar o status dos pedidos de acesso. As Figuras 4 e 5 servem como exemplo para ilustrar o acompanhamento dos pedidos de acesso à informação nos portais eletrônicos que disponibilizam esta ferramenta e retratam a situação em que ficaram os pedidos que simplesmente foram negligenciados, nem atendidos, nem negados.

Figura 4. Status do pedido de acesso não respondido pelo município de Caibaté

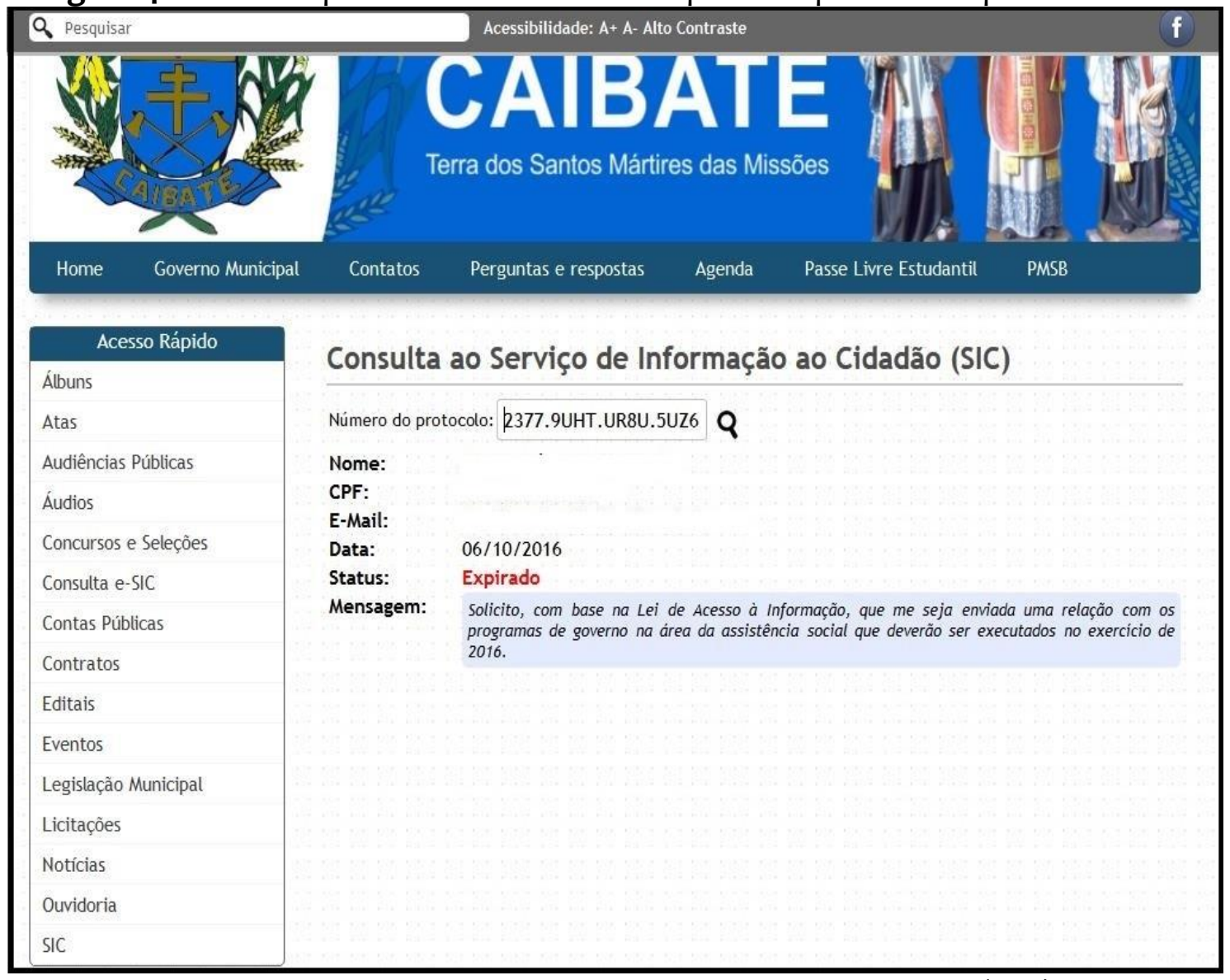

Fonte: Coleta de dados da pesquisa no portal eletrônico do município de Caibaté (2017). 
Figura 5. Status de um dos pedidos de acesso não respondido pelo município de Dezesseis de Novembro

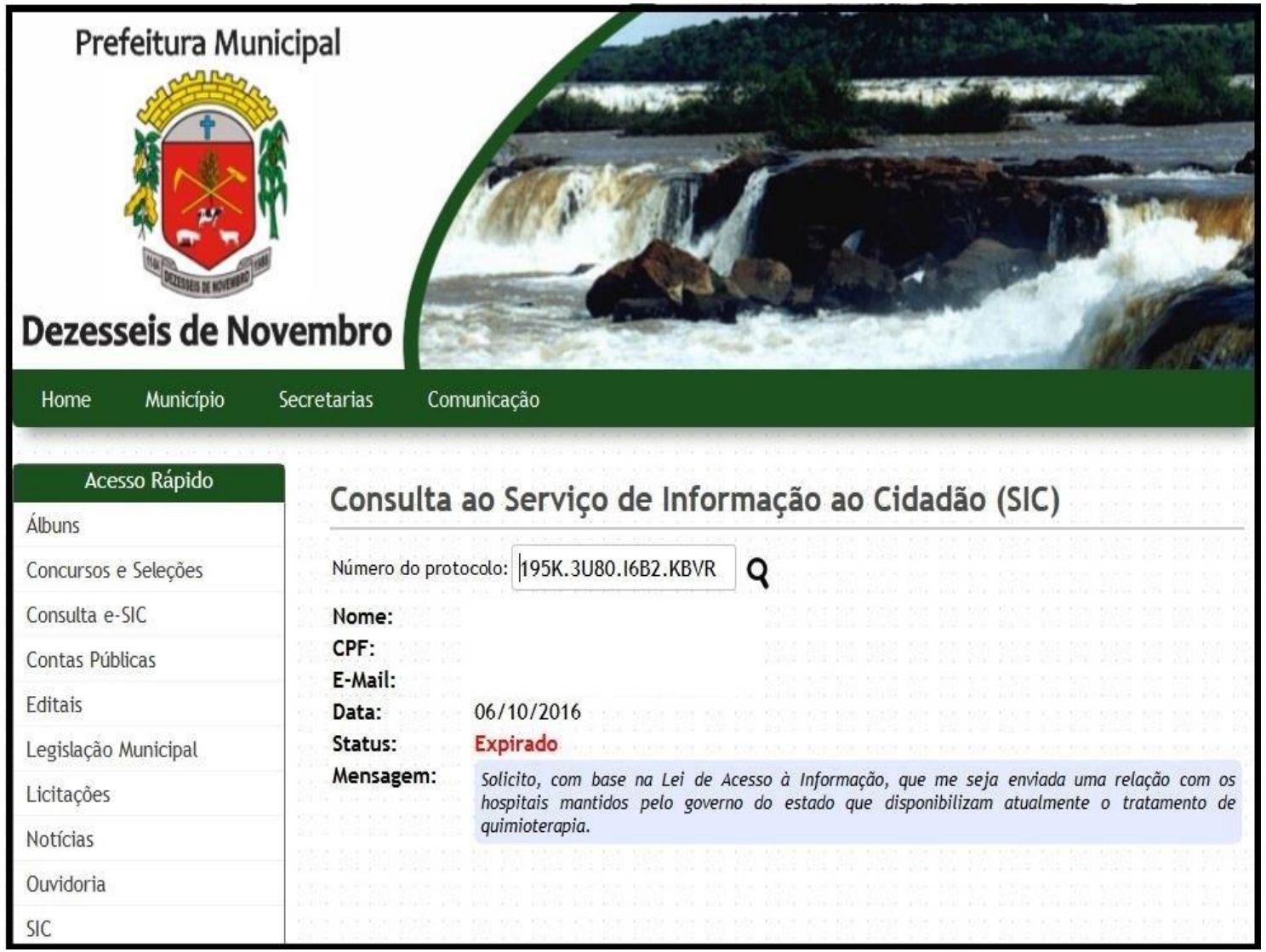

Fonte: Coleta de dados da pesquisa no portal eletrônico do município de Dezesseis de Novembro (2017).

Ao que se refere aos meios para efetivar o pedido de informação, a forma mais frequente de solicitação encontrada foi o e-SIC, correspondendo a $84 \%$ da amostra, ou seja 21 municípios. Nos outros 4 municípios (Bossoroca, Dezesseis de Novembro, São Pedro do Butiá e Ubiretama) pode-se encaminhar o pedido por meio de formulários eletrônicos no "Fale Conosco" ou na Ouvidoria, canais que representam modelos básicos de interação em portais eletrônicos institucionais, sendo possível encaminhar o pedido de informação, a todos os municípios. Como resultado, tem-se o Quadro 4 que representa o retorno dos municípios para cada um destes pedidos. 


\section{Quadro 4. Monitoramento de respostas aos pedidos de acesso à informação}

\begin{tabular}{|c|c|c|c|c|c|c|c|c|}
\hline \multirow[b]{2}{*}{ Município } & \multicolumn{4}{|c|}{$\begin{array}{l}\text { Cumpre os prazos para } \\
\text { resposta das } \\
\text { solicitações? }\end{array}$} & \multicolumn{4}{|c|}{$\begin{array}{l}\text { Respondeu ao que se perguntou, atendendo ao } \\
\text { pedido de informação? }\end{array}$} \\
\hline & 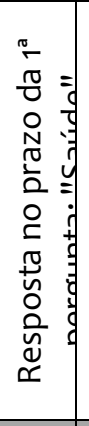 & 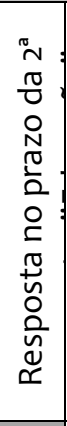 & 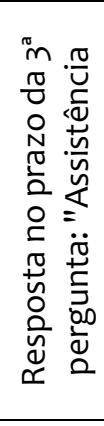 & 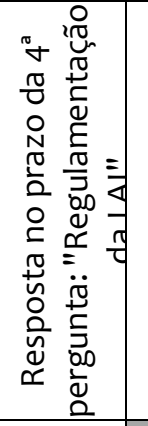 & 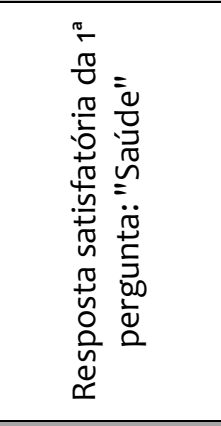 & 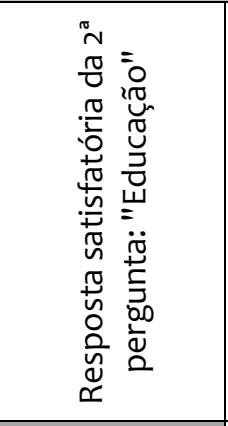 & 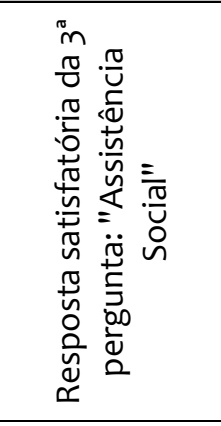 & 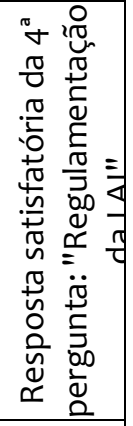 \\
\hline Bossoroca & $x$ & $x$ & & & $\mathrm{x}$ & $\mathrm{x}$ & & \\
\hline Caibaté & $x$ & $x$ & & $x$ & $x$ & $x$ & & $x$ \\
\hline Cerro Largo & $x$ & $x$ & & $x$ & $x$ & $x$ & & $x$ \\
\hline \multicolumn{9}{|l|}{$\begin{array}{l}\text { Dezesseis de } \\
\text { Novembro }\end{array}$} \\
\hline \multicolumn{9}{|l|}{ Entre ljuís } \\
\hline Eugênio de Castro & $\mathrm{x}$ & $\mathrm{x}$ & $\mathrm{x}$ & $\mathrm{x}$ & $\mathrm{x}$ & $\mathrm{x}$ & Parcialmente & $\mathrm{x}$ \\
\hline \multicolumn{9}{|l|}{ Garruchos } \\
\hline Giruá & $\mathrm{X}$ & $\mathrm{X}$ & $\mathrm{x}$ & $\mathrm{X}$ & $\mathrm{X}$ & $\mathrm{x}$ & Parcialmente & $\mathrm{X}$ \\
\hline \multicolumn{9}{|l|}{$\begin{array}{l}\text { Guarani das } \\
\text { Missões }\end{array}$} \\
\hline Mato Queimado & $x$ & $x$ & $x$ & $x$ & $x$ & $x$ & $x$ & $x$ \\
\hline \multicolumn{9}{|l|}{ Pirapó } \\
\hline Porto Xavier & $\mathrm{x}$ & $\mathrm{X}$ & $\mathrm{X}$ & $\mathrm{X}$ & $x$ & $\mathrm{X}$ & $\mathrm{X}$ & $\mathrm{X}$ \\
\hline Rolador & $\mathrm{X}$ & & & & $\mathrm{X}$ & & & \\
\hline \multicolumn{9}{|l|}{ Roque Gonzales } \\
\hline \multicolumn{9}{|l|}{$\begin{array}{l}\text { Salvador das } \\
\text { Missões }\end{array}$} \\
\hline Santo Ângelo & $\mathrm{X}$ & $\mathrm{X}$ & $\mathrm{x}$ & $\mathrm{X}$ & Parcialmente & Parcialmente & $\mathrm{X}$ & $\mathrm{X}$ \\
\hline $\begin{array}{l}\text { Santo Antônio das } \\
\text { Missões }\end{array}$ & $\mathrm{X}$ & $\mathrm{x}$ & $\mathrm{x}$ & $\mathrm{x}$ & Parcialmente & Parcialmente & Parcialmente & \\
\hline São Luiz Gonzaga & $\mathrm{x}$ & $\mathrm{x}$ & & $\mathrm{x}$ & Parcialmente & Parcialmente & & $x$ \\
\hline \multicolumn{9}{|l|}{$\begin{array}{l}\text { São Miguel das } \\
\text { Missões }\end{array}$} \\
\hline São Nicolau & $x$ & $x$ & $x$ & $x$ & $x$ & Parcialmente & $x$ & $x$ \\
\hline $\begin{array}{l}\text { São Paulo das } \\
\text { Missões }\end{array}$ & $\mathrm{x}$ & $\mathrm{x}$ & $\mathrm{x}$ & $\mathrm{x}$ & $\mathrm{x}$ & $\mathrm{x}$ & Parcialmente & $\mathrm{x}$ \\
\hline $\begin{array}{l}\text { São Pedro do } \\
\text { Butiá }\end{array}$ & $\mathrm{x}$ & & $\mathrm{x}$ & & $\mathrm{x}$ & & $\mathrm{x}$ & \\
\hline \multicolumn{9}{|l|}{ Sete de Setembro } \\
\hline Ubiretama & $\mathrm{X}$ & $\mathrm{x}$ & $\mathrm{x}$ & $\mathrm{x}$ & Parcialmente & Parcialmente & Parcialmente & $\mathrm{x}$ \\
\hline $\begin{array}{l}\text { Vitória das } \\
\text { Missões }\end{array}$ & $\mathrm{X}$ & $\mathrm{x}$ & & $\mathrm{x}$ & $x$ & $\mathrm{x}$ & & $\mathrm{x}$ \\
\hline
\end{tabular}

Fonte: Dados da pesquisa (2017).

Nota: $X$ corresponde ao atendimento da solicitação, parcialmente significa que o pedido foi atendido em parte e branco significa que o pedido não foi atendido.

De acordo com o Quadro 4, observou-se que 9 municípios (36\%) não atenderam ao pedido de acesso à informação, deixando de cumprir com a transparência passiva, isto é, para estes municípios a solicitação foi encaminhada via 
portal eletrônico, mas não houve atendimento a solicitação. Essa é a realidade dos seguintes municípios da região: Dezesseis de Novembro, Entre ljuís, Garruchos, Guarani das Missões, Pirapó, Roque Gonzales, Salvador das Missões, São Miguel das Missões e Sete de Setembro.

Em uma pesquisa desenvolvida por Raupp (2016) sobre a realidade da transparência passiva em prefeituras dos maiores municípios brasileiros, os resultados apresentam índices bem maiores, apontando que (73,85\%) das prefeituras não atendem aos pedidos de informações encaminhados ou atendem de forma considerada insuficiente e fora do prazo legal. Michener, Moncau e Velasco (2014) realizaram duas avaliações para analisar a aplicação da LAI, enviando 717 pedidos de acesso à informação, sendo 453 deles na avaliação geral e 264 na avaliação do Poder Judiciário, para 173 órgãos públicos dos três poderes e de oito unidades federativas (nos estados de São Paulo, Minas Gerais e Rio de Janeiro, bem como em suas respectivas capitais, além do Distrito Federal e da União). Houve variação considerável entre as diversas unidades federativas, sendo que na pesquisa geral, apenas 315 pedidos (69\%) foram respondidos e no Judiciário, apenas 160 (61\%), sendo que destes somente 69 (26\%) foram considerados como respostas suficientes. Os resultados da pesquisa de Michener, Moncau e Velasco (2014) coadunam com a pesquisa em curso, sendo que em média, um de cada três pedidos encaminhados foi completamente ignorado, alcançando uma taxa de 33\% de não atendimento aos pedidos de acesso a informação.

O fato de as prefeituras não atenderem as solicitações encaminhadas, negligenciando ao pedido de acesso a informação por parte dos pesquisadores (no caso representando um cidadão comum), vem a confirmar o que afirmam Portella e Côrtes (2015, p. 1106), que "não há outra alternativa a considerar senão a de equiparar um SIC-eletrônico inoperante à inexistência de tal sistema, ao menos para fins de enquadramento normativo". Para estes autores, não há valor nenhum na criação e implantação de uma página indicativa do SIC, se os cidadãos não forem atendidos em suas consultas, pois a finalidade deste instrumento virtual é incentivar e estreitar a relação entre governo e cidadão, além de proporcionar maior praticidade no exercício da cidadania e participação popular.

Em 14 dos municípios, correspondendo a 56\% da amostra, os pedidos de acesso foram atendidos parcialmente 3 : Bossoroca, Caibaté, Cerro Largo, Eugênio de Castro, Giruá, Rolador, Santo Ângelo, Santo Antônio das Missões, São Luiz Gonzaga, São Nicolau, São Paulo das Missões, São Pedro do Butiá, Ubiretama e Vitória das Missões. Este resultado corrobora com o estudo de Pinho (2008), em nove portais eletrônicos dos estados considerados mais desenvolvidos do país e do Distrito Federal, que constatou que o problema não é de falta de tecnologia, não que esta não deva ser aperfeiçoada e melhorada constantemente, mas sim de cultura política e desenvolvimento político, o que tem impedido os governos de incorporar a cultura de utilização das TICs. Raupp (2016) ao investigar a realidade da transparência passiva em prefeituras dos maiores municípios brasileiros, observou que o descumprimento da LAI ocorre na maioria dos municípios, ora por problemas no portal, ora por problemas no retorno às solicitações de informações.

3 Classificação dada à resposta a pedido de acesso em que a informação solicitada foi franqueada parcialmente ao requerente (CGU, 2015). 
Somente em 2 municípios, correspondendo a (8\%) do total da amostra, os pedidos de acesso à informação foram totalmente atendidos: Porto Xavier e Mato Queimado. Este resultado corrobora com o estudo de Raupp (2016), que mesmo tendo identificado taxas de respostas correspondentes a 22,26\%, afirma haver uma inversão entre a regra e a exceção, pelo fato de ser a minoria dos municípios os que atendem a legislação, quando deveria ocorrer o contrário. A Tabela 1 apresenta um resumo da transparência passiva dos municípios do COREDE Missões.

Tabela 1. Síntese da transparência passiva dos municípios do COREDE Missões

\begin{tabular}{lcc}
\hline \multicolumn{1}{c}{ Categorias } & $\mathbf{N}^{\circ}$. & Percentual \\
\hline Municípios em que não foi possível encaminhar o pedido de acesso à & & \\
informação. & 0 & $0 \%$ \\
Municípios cuja solicitação foi encaminhada, mas não houve retorno. & $36 \%$ \\
Municípios em que a solicitação foi encaminhada e houve retorno parcial. & 14 & $56 \%$ \\
Municípios em que a solicitação foi encaminhada e houve retorno satisfatório. & 2 & $8 \%$ \\
\hline Total & 25 & $100 \%$ \\
\hline
\end{tabular}

Fonte: Dados da Pesquisa (2017).

De modo geral, compreende-se a partir da Tabela 1 que $36 \%$ dos municípios foram considerados pouco transparentes na forma passiva. Em $56 \%$ dos municípios houve retorno parcial aos pedidos de acesso à informação, sendo assim considerados por não atenderem plenamente ao que foi solicitado, encaminhando resposta que não atendia ao requerido e somente ( $8 \%$ ) dos municípios podem ser considerados transparentes na forma passiva. O mau desempenho dos municípios na questão da transparência passiva inviabiliza a essência da LAI, visto que esta legislação versa sobre a regulamentação da transparência passiva e sobre a classificação de documentos, além de incorporar informações obrigatórias a efetivação da transparência ativa (ARRUDA, 2016).

Assim, após a avaliação da primeira categoria (Regulamentação da LAI), a qual atribuiu $25 \%$ da nota, os pedidos de acesso, correspondem a segunda categoria de avaliação (transparência passiva) e equivalem a 75\% da nota geral e atribuíram aos municípios uma nota que incorporando-se à primeira, gerou um ranking de transparência, sendo que dos municípios avaliados apenas um atingiu a nota máxima, conforme apresentado na Tabela 2, que apresenta o resultado final da aplicação da metodologia da EBT.

Tabela 2. Ranking dos municípios do COREDE Missões avaliados na EBT (continua)

\begin{tabular}{lcc}
\hline \multicolumn{1}{c}{ Município } & Nota EBT & Posição na EBT \\
\hline Porto Xavier & 10,00 & $1^{\circ}$ \\
Giruá & 9,16 & $2^{\circ}$ \\
São Nicolau & 9,16 & $3^{\circ}$ \\
São Paulo das Missões & 9,16 & $4^{\circ}$ \\
Cerro Largo & 8,75 & $5^{\circ}$ \\
Mato Queimado & 8,61 & $6^{\circ}$ \\
Caibaté & 8,47 & $7^{\circ}$ \\
São Luiz Gonzaga & 7,36 & $8^{\circ}$ \\
\hline
\end{tabular}


(conclusão)

\begin{tabular}{lcc}
\hline \multicolumn{1}{c}{ Município } & Nota EBT & Posição na EBT \\
\hline Santo Ângelo & 6,94 & $9^{\circ}$ \\
Vitória das Missões & 6,52 & $10^{\circ}$ \\
Eugênio de Castro & 6,38 & $11^{\circ}$ \\
Santo Antônio das & & \\
Missões & 5,55 & $12^{\circ}$ \\
Ubiretama & 5,27 & $13^{\circ}$ \\
Rolador & 5,00 & $14^{\circ}$ \\
São Pedro do Butiá & 4,44 & $15^{\circ}$ \\
Roque Gonzales & 3,88 & $16^{\circ}$ \\
São Miguel das Missões & 3,61 & $17^{\circ}$ \\
Sete de Setembro & 3,61 & $18^{\circ}$ \\
Dezesseis de Novembro & 3,33 & $19^{\circ}$ \\
Guarani das Missões & 3,33 & $20^{\circ}$ \\
Pirapó & 3,33 & $21^{\circ}$ \\
Garruchos & 3,05 & $22^{\circ}$ \\
Entre ljuís & 2,78 & $23^{\circ}$ \\
Bossoroca & 2,77 & $24^{\circ}$ \\
Salvador das Missões & 2,50 & $25^{\circ}$ \\
\hline
\end{tabular}

Fonte: Dados da pesquisa (2017).

Conforme apresentado na Tabela 2, o município de Porto Xavier alcançou nota 10,00 na Escala, atendendo a todos os quesitos avaliados, tanto na categoria de regulamentação da LAI, onde foi observada a disponibilização no portal eletrônico de todos os itens pesquisados, bem como a própria regulamentação da Lei 12.527/2011 em nível municipal, por meio da Lei Municipal 2.249, de 04 de setembro de 2012, quanto na categoria da transparência passiva, atendendo aos quatro pedidos de acesso à informação encaminhados.

\section{Considerações Finais}

Este estudo teve por objetivo verificar o grau de cumprimento às normas da Lei de Acesso à Informação (Lei 12.527/2011) e a realidade da transparência passiva, por meio da aplicação da EBT nos portais eletrônicos dos municípios do COREDE Missões. Pode-se mencionar que a realidade dos municípios investigados não se apresenta de forma satisfatória, sendo que $36 \%$ não atenderam ao pedido de acesso à informação, deixando de cumprir com a transparência passiva, 56\% atenderam parcialmente e apenas $8 \%$ do total da amostra, atendeu totalmente aos pedidos de acesso.

Constatou-se que muito se tem a avançar para que na região de abrangência do COREDE Missões alcance efetividade a LAI, de forma que a mesma não seja considerada como uma obrigação jurídica, mas como uma política pública de transparência e accountability, que permita através da disponibilização do acesso à informação o exercício da cidadania e o consequente controle social. Nesta perspectiva, Araújo e Mello (2016), em uma avaliação da lei de acesso à informação brasileira, discorrem sobre a prevalência nos municípios de uma "cultura do pen 
drive", a qual não se trata somente da cultura do sigilo, mas da prática da apropriação pessoal, por parte do servidor público, da informação sob seu gerenciamento. Este servidor não compartilha a informação nem sequer com os demais servidores, muito menos com o cidadão.

Uma pesquisa sobre valores, conhecimento e cultura de acesso à informação pública no Poder Executivo Federal Brasileiro, foi promovida pela Controladoria-Geral da União - CGU (CGU, 2011) em parceria com a Organização das Nações Unidas para a Educação, a Ciência e a Cultura (UNESCO), com servidores públicos, para avaliar a política de acesso à informação pública. Os resultados apontam que, ainda que os servidores percebam como adequada a política de transparência e acesso às informações, a cultura do segredo permanecia nas várias opiniões quanto aos fatores negativos à concretização da legislação de acesso e transparência. Um exemplo demonstrado contempla as solicitações excessivas e descabidas, má utilização das informações, vantagens desproporcionais e indevidas para grupos de interesse bem situados para obter essas informações e usá-las para seus fins privados e o uso político das informações obtidas. Por outro lado, os participantes reconheceram pontos positivos que poderiam ocorrer da legislação, como por exemplo, mais transparência sobre as atividades da Administração Pública, redução, combate e prevenção da corrupção e fortalecimento da credibilidade e melhoria da imagem da Administração Pública (CGU, 2011).

Os resultados obtidos contribuem no campo prático e teórico. Em termos práticos, apresenta-se um diagnóstico da regulamentação da LAI e da atual situação da transparência passiva na gestão pública municipal no âmbito do COREDE Missões, permitindo aos cidadãos conhecer melhor o ambiente onde vivem e investem, afim de que possam refletir sobre a eficiência na gestão pública e a suficiência ou não das informações disponibilizadas, para assim poder intervir no processo de formulação de políticas públicas que possam auxiliar no desenvolvimento regional. Teoricamente os resultados da pesquisa contribuem no sentido de propor-se a investigar um tema que segundo Raupp (2016, p.49) "é evidente a carência de estudos sobre transparência, particularmente em relação à transparência passiva, tema discutido de forma incipiente em eventos e periódicos nacionais".

Cabe destacar que ainda que o estudo tenha rigor metodológico, é necessário apontar suas limitações. Uma delas é o fato de no ano de 2016 ter ocorrido eleições para o pleito municipal, acarretando na mudança de governo na maioria dos municípios que compõe a amostra, o que pode ter influenciado no atendimento aos pedidos de acesso. Outra limitação diz respeito à exiguidade de pesquisas sobre a transparência passiva e a falta de uniformidade na apresentação dos conteúdos nos portais eletrônicos, surgindo destas limitações campo para futuras pesquisas.

Adicionalmente, como sugestão para outras pesquisas deixa-se a indicação de um estudo sobre a forma e o título que as prefeituras utilizam na evidenciação de seus relatórios, afim de que se crie um dicionário de dados, com todos os possíveis "nomes" utilizados para o tratamento do mesmo conteúdo; bem como sobre a temática da transparência passiva, em razão da raridade de pesquisas sobre o assunto. 


\section{REFERÊNCIAS}

ABREU, J. C. A. de; LEOPOLDINO, C. B.; MELO, D. R. A. Democracia Participativa e Internet: Uma análise sobre os Portais dos municípios da Região das Agulhas Negras/RJ. In: EnAPG - Encontro de Administração Pública e Governança. Salvador/BA - 12 a 14 de novembro de 2008. Disponível em: <http://www.anpad.org.br/admin/pdf/EnAPG267.pdf.>. Acesso em: Mar. 2017.

ANGÉLICO, F. Lei de acesso à informação pública e seus possíveis desdobramentos à accountability democrática no Brasil. 2012. 133 f. Dissertação (Mestrado em Administração Pública e Governo) - Fundação Getúlio Vargas, Escola de Administração de Empresas, São Paulo, 2012.

ARAÚJO, T. F.; MELLO, M. T. L. Avaliação da Lei de Acesso à Informação Brasileira: uma abordagem metodológica interdisciplinar. Revista de Estudos Empíricos em Direito, vol. 3, n. 2, jul. 2016, p. 113-134, 2016.

ARRUDA, C. E. G. de. Transparência Subnacional: um estudo das variáveis determinantes para o atendimento da lei de acesso à informação nos municípios brasileiros. 2016. 115 f. Dissertação (Mestrado em Administração Pública e Governo) - Fundação Getúlio Vargas, Escola de Administração de Empresas, São Paulo. 2016.

ATLAS Socieconômico do Rio Grande do Sul. Conselhos Regionais de

Desenvolvimento - COREDEs. Disponível em: <http://www.atlassocioeconomico.rs.gov.br/upload/MAPAS_A4_Missoes.pdf>. Acesso em: 26 nov. 2015.

BRASIL. Aprova o texto da Convenção das Nações Unidas contra a Corrupção. Decreto $\mathrm{N}^{\circ} 348$, de 18 de maio de 2005. Disponível em: <http://www2.camara.leg.br/legin/fed/decleg/2005/decretolegislativo-348-18-maio2005-536880-convencao-28439-pl.html>. Acesso em: jul. 2016.

. Promulga a Convenção das Nações Unidas contra a Corrupção. Decreto $N^{\circ}$ 5.687, de 31 de janeiro de 2006. Disponível em: <http://www.planalto.gov.br/ccivil_03/_At02004-2006/2006/Decreto/D5687.htm>. Acesso em: jul. 2016.

. Lei da Transparência. Lei Complementar n¹31, de 27 de Maio de 2009. Presidência da República. Casa Civil. Subchefia para Assuntos Jurídicos. Brasília, 2009. Disponível em: <http://www.planalto.gov.br/ccivil_03/leis/LCP/Lcp131.htm>. Acesso em: jul. 2016.

. Lei de Acesso a Informações Públicas. Lei n 12.527, de 18 de novembro de 2011. Presidência da República. Casa Civil. Subchefia para Assuntos Jurídicos. Brasília, 2011. Disponível em: < http://www.planalto.gov.br/ccivil_03/_ato20112014/2011/lei/l12527.htm>. Acesso em: jul. 2016. 
. Regulamenta a Lei $\mathrm{n}^{\mathrm{0}} \mathbf{1 2 . 5 2 7}$, de 18 de novembro de 2011. Decreto $\mathrm{N}^{\circ}$ 7.724/2012, de 16 de maio de 2012. Presidência da República. Casa Civil. Subchefia para Assuntos Jurídicos. Brasília, 2012. Disponível em:

http://www.planalto.gov.br/ccivil_03/_ato2011-2014/2012/decreto/d7724.htm. Acesso em: mar. 2017.

CASALI, C. J. L. Portal Transparência Bahia: um passo para a construção de um estado mais transparente. 2014. 100 f. Dissertação (Mestrado Multidisciplinar e Profissionalizante em Desenvolvimento e Gestão Social) - Universidade Federal da Bahia, Escola de Administração, Salvador, 2014.

CGU - Controladoria Geral da União. Diagnóstico sobre valores, conhecimento e cultura de acesso à informação pública no poder executivo federal brasileiro. Disponível em: http://www.acessoainformacao.gov.br/central-deconteudo/publicacoes/arquivos/pesquisadiagnostico.pdf. Acesso em: 01 mar. 2017.

. Controladoria Geral da União. Secretaria de Prevenção da Corrupção e Informações Estratégicas. Manual da Lei de Acesso à Informação para Estados e Municípios. $1^{a}$ Edição. Brasília - DF. 2013. Disponível em: <http://www.cgu.gov.br/Publicacoes/transparencia-publica/brasiltransparente/arquivos/manual_lai_estadosmunicipios.pdf>. Acesso em: 01 set. 2016.

. Controladoria Geral da União. EBT. Escala Brasil Transparente. Disponível em <http://www.cgu.gov.br/assuntos/transparencia-publica/escala-brasiltransparente/arquivos/checklist-ebt-2.xls>. Acesso em: 30 set. 2016.

DANTAS, Cristovan Grazina. Transparência e Controle Social na Gestão Pública Brasileira: um estudo de caso da legislação, ferramentas e avanços recentes. 2015. 63 f. Trabalho Conclusão de Curso (Graduação em Gestão de Políticas Públicas) Universidade Estadual de Campinas, Limeira, 2015.

FILGUEIRAS, Fernando. Além da transparência: accountability e política da publicidade. Lua Nova, v. 84, p. 65-94, 2011.

GIL, A. C. Métodos e Técnicas de Pesquisa Social. 6. ed. São Paulo: Atlas, 2008.

GOMES FILHO, A. B. O desafio de implementar uma gestão pública transparente. In: CONGRESO INTERNACIONAL DEL CLAD SOBRE LA REFORMA DEL ESTADO Y DE LA ADMINISTRACIÓN PÚBLICA, X., 2005, Santiago, Chile. Anais... Santiago, Chile. 2005.

HOCH, Patrícia Adriani; RIGUI, Lucas Martins; SILVA, Rosane Leal da. Desafios à concretização da transparência ativa na internet, à luz da Lei de Acesso à Informação Pública: análise dos portais dos Tribunais Regionais Federais. REDESG Revista Direitos Emergentes na Sociedade Global, Santa Maria, v. 1, n. 2, p.257-286, 2012. 
MALHOTRA, N. Pesquisa de marketing: uma orientação aplicada. $3^{\mathrm{a}}$ Ed. Porto Alegre: Bookman, 2001.

MICHENER, R. G.; MONCAU, L. F. M.; VELASCO, R. B. Estado brasileiro e transparência: avaliando a aplicação da lei de acesso à informação. Rio de Janeiro: [s.n.], 2014.

PINHO, J. A. G. de. Internet, governo eletrônico, sociedade e democracia no Brasil: algumas questões básicas em debate. Revista VeraCidade, v. 3, n. 3, p. 1-20, 2008.

PORTELLA, A.; CÔRTES, A. Q. Análise crítica do acesso à informação pública nos municípios baianos com mais de 100 mil habitantes. Revista de Direito da Cidade, vol. 07, nº3. pp.1092-1111, 2015.

RAUPP, F. M. Realidade da transparência passiva em prefeituras dos maiores municípios Brasileiros. Revista Contemporânea de Contabilidade. UFSC, Florianópolis, v.13, n. 30, p. 34-52, set./dez. 2016.

SILVA, L. M. Contabilidade governamental: um enfoque administrativo. 8 ed. São Paulo: Atlas, 2009.

SILVESTRE, A. L.. Análise de Dados, Estatística Descritiva. Lisboa: Escolar Editora, 2007.

SOUZA, A. C. et al. A relevância da transparência na gestão pública municipal.

Revista Campus. Paripiranga, v. 2, n. 5, p. 6-20, 2009.

ZUCOLOTTO, R.; TEIXEIRA, M. A. C.; RICCIO, E. L. Transparência: reposicionando o debate. Revista Contemporânea de Contabilidade. UFSC, Florianópolis, v. 12, n. 25, p. 137-158, jan./abr. 2015.

Monize Sâmara Visentini. Doutora em Administração pela Universidade Federal do Rio Grande do Sul (UFRGS) e Mestre em Administração pela Universidade Federal de Santa Maria (UFSM). Professora Adjunta do Curso de Administração da Universidade Federal da Fronteira Sul (UFFS). Professora do Quadro permanente do Programa de Mestrado em Desenvolvimento e Políticas Públicas (UFFS).monize.visentini@uffs.edu.br

Micheli dos Santos. Mestre em Desenvolvimento e Políticas Públicas Universidade Federal da Fronteira Sul (UFFS). Graduada em Administração pela Universidade Regional Integrada do Alto Uruguai e das Missões (2007) e especialista em Administração Estratégica pela UNIASSELVI. Assistente em Administração da Universidade Federal da Fronteira Sul, campus Cerro Largo/RS.micheli.santos@uffs.edu.br 
Como citar: VISENTINI, Monize Sâmara; SANTOS, Micheli dos. Panorama da transparência passiva e da regulamentação da Lei de Acesso à Informação a partir da Escala Brasil Transparente (EBT) nos municípios do COREDE Missões. Redes (St. Cruz Sul, Online), Santa Cruz do Sul, v. 25, n. 1, jan. 2020. ISSN 1982-6745. DOI: https://doi.org/10.17058/redes.v25i1.11205.

\section{CONTRIBUIÇÃO DE CADA AUTORA}

Fundamentação teórico-conceitual e problematização: Micheli dos Santos e Monize Sâmara Visentini

Pesquisa de dados e análise estatística: Micheli dos Santos e Monize Sâmara Visentini Elaboração de figuras e tabelas: Micheli dos Santos

Fotos: não se aplica

Elaboração e redação do texto: Micheli dos Santos e Monize Sâmara Visentini Seleção das referências bibliográficas: Micheli dos Santos 